\title{
Spray-dried Spirulina platensis as an effective ingredient to improve yogurt formulations: Testing different encapsulating solutions
}

\author{
Samara C. da Silva ${ }^{\mathrm{a}, \mathrm{b}, \mathrm{c}}$, Isabel P. Fernandes ${ }^{\mathrm{a}, \mathrm{b}}$, Lillian Barros ${ }^{\mathrm{a}}$, Ângela Fernandes ${ }^{\mathrm{a}}$, \\ Maria José Alves $^{\mathrm{a}}$, Ricardo C. Calhelha ${ }^{\mathrm{a}}$, Carla Pereira ${ }^{\mathrm{a}}$, João C.M. Barreira ${ }^{\mathrm{a}}$, Yaidelin Manrique ${ }^{\mathrm{b}}$, \\ E. Colla ${ }^{\mathrm{c}}$, Isabel C.F.R. Ferreira ${ }^{\mathrm{a}, *}$, M. Filomena Barreiro ${ }^{\mathrm{a}, \mathrm{b}, *}$ \\ ${ }^{a}$ Centro de Investigação de Montanha (CIMO), Instituto Politécnico de Bragança, Campus Santa Apolónia, 5300-253 Bragança, Portugal \\ ${ }^{\mathrm{b}}$ Laboratory of Separation and Reaction Engineering - Laboratory of Catalysis and Materials (LSRE-LCM), Polytechnic Institute of Bragança, Campus Santa Apolónia, \\ 1134, 5301-857 Bragança, Portugal \\ ${ }^{\mathrm{c}}$ Departamento Acadêmico de Alimentos (DAALM) - Programa de Pós-graduação em Tecnologia de Alimentos (PPGTA) - Universidade Tecnológica Federal do Paraná, \\ Câmpus Medianeira, 85884-000 Paraná, Brazil
}

\section{A R T I C L E I N F O}

\section{Keywords:}

Spirulina platensis

Nutritional and chemical composition

Spray drying

Microencapsulation

Crosslinking

Bioactivity

Functional yogurts

\begin{abstract}
A B S T R A C T
The consumption of foods functionalized with spirulina might have positive health effects. However, spirulinabased food products are usually associated with unpleasant flavor and odor, and can present non-homogeneous appearance, impairing consumers' acceptance. Moreover, it is important to assure bioactivity maintenance. To develop a novel food ingredient, spirulina was chemically characterized, and spray-dried using two encapsulating materials: i) maltodextrin and ii) maltodextrin crosslinked with citric acid. Thereafter, free and encapsulated spirulina were evaluated for their bioactive properties. Microencapsulated spirulina presented higher thermal stability than the base materials, while showing better anti-inflammatory activity without exerting cytotoxicity. Free and encapsulated spirulina were further added to yogurts to validate their suitability as functionalizing agents. Yogurts added with encapsulated spirulina presented a more homogeneous appearance, and the best solution was spirulina encapsulated in maltodextrin crosslinked with citric acid, considering the nutritional profile, attractive color, and improved antioxidant activity throughout storage time.
\end{abstract}

\section{Introduction}

Functional foods have become a trend in recent years due to the increasing number of consumers looking for nutritious and safe foods with health benefits, particularly of natural origin (Bharat Helkar \& Sahoo, 2016; Bimbo et al., 2017). In this context, microalgae have become innovative and promising resources to obtain functional ingredients and add nutritional value to foods. In fact, microalgae are considered natural sources of bioactive compounds, vitamins, proteins and essential amino acids, monounsaturated and polyunsaturated fatty acids, polysaccharides, minerals, pigments, enzymes, and fibres, and their consumption might have positive effects on consumers' health (Christaki, Florou-Paneri, \& Bonos, 2011; Matos, Cardoso, Bandarra, \& Afonso, 2017). To validate this assumption, various combinations of microalgae are already commercially available, either as capsules, powders, liquids or as nutritional supplements (Gouveia, Batista, Sousa, Raymundo, \& Bandarra, 2008).
Spirulina platensis, also known as spirulina or Arthrospira, is a bluegreen filamentous prokaryotic cyanobacterium with a protein content of 55-70\%, which includes the entire range of essential amino acids. It also contains vitamins (B1, B2, B12, E, and provitamin A), minerals (Fe, $\mathrm{Mg}, \mathrm{Ca}, \mathrm{P}, \mathrm{Cr}, \mathrm{Cu}, \mathrm{Na}, \mathrm{Zn}$ ), pigments (phycocyanin, chlorophylls and carotenoids), and essential fatty acids ( $\gamma$-linolenic acid) (Soni, Sudhakar, \& Rana, 2017; Wan, Wu, \& Kuča, 2016). Spirulina is generally recognized as safe (GRAS) for human consumption (Food \& Administration, 2002), having been added to some food products such as ice cream and cheese (Agustini et al., 2016), bread (Ak et al., 2016; Hafsa, Amel, Samia, Sidahmed, \& Ali, 2014), and pasta (Özyurt et al., 2015).

Yogurt is a very popular food product, standing out as one of the most consumed fermented dairy products in the world. Due to its high consumption, it might be a good vehicle to ensure and improve the daily intake of nutrients, which can prevent diseases and bring positive impacts on consumers' health (Gahruie, Eskandari, Mesbahi, \&

\footnotetext{
* Corresponding authors at: Centro de Investigação de Montanha (CIMO), Instituto Politécnico de Bragança, Campus Santa Apolónia, 5300-253 Bragança, Portugal (Isabel C.F.R. Ferreira and M. Filomena Barreiro).

E-mail addresses: iferreira@ipb.pt (I.C.F.R. Ferreira), barreiro@ipb.pt (M. Filomena Barreiro).
} 
Hanifpour, 2015). Thus, the incorporation of functional ingredients into food matrices, such as yogurt, has been carried out for selected purposes, such as the incorporation of curcumin (E100) (Almeida et al., 2018), encapsulated echium oil, phytosterols, and sinapic acid (Comunian et al., 2017), encapsulated fish oil (Ghorbanzade, Jafari, Akhavan, \& Hadavi, 2017), and natural additives from chamomile and fennel (Caleja et al., 2016). In fact, the market of functional ingredients has potential for expansion, representing one of the top interests of food industry (Dias, Botrel, Fernandes, \& Borges, 2017). In its native form, spirulina was previously added to yogurts (Agustini, Soetrisnanto, \& Maruf, 2017; Barkallah et al., 2017), but it typically confers a quite unpleasant flavour and odour, besides losing some of its bioactivity and presenting a non-homogeneous appearance. Spray drying, one of the most widely used encapsulation techniques in food industry, might represent an effective solution to this problem. In addition, it is considered as a versatile method, suitable for continuous production, thereby resulting in an economic industrial scalable process (Dias, Ferreira, \& Barreiro, 2015). Overall, encapsulation techniques contribute to increase the stability of bioactive compounds, delivering active ingredients to specific sites, and avoid degradation processes due to external factors (Wen, Chen, \& Alany, 2014).

Maltodextrin (MD) is widely used as wall material, mostly due to its effectiveness, low cost, neutral flavour and aroma, and high water solubility (Ribeiro et al., 2015; Zhang et al., 2018). Moreover, when combined with citric acid and after thermal heating, it forms a polymeric network (crosslinking) due to the esterification reaction between the hydroxyl groups of maltodextrin and the carboxyl groups of citric acid (Castro-Cabado, Parra-Ruiz, Casado, \& San Román, 2016). In addition to increasing the thermal and mechanical resistance (CastroCabado, Casado, \& San Román, 2016b), these crosslinking reactions preserve the bioactivity of the encapsulated agents (Francisco et al., 2018).

In this work, Spirulina platensis was incorporated in yogurts in three forms: free, microencapsulated in MD and microencapsulated in MD crosslinked with citric acid, all previously evaluated concerning chemical composition and bioactivity. These ingredients were further used to develop different yogurt formulations with the aim of improving their nutritional value and supplying them with the bioactive compounds found in spirulina.

\section{Materials and methods}

\subsection{Samples, standards and reagents}

Spirulina platensis was acquired at a local shop (Bragança, Portugal) specialized in dietetic products. Samples were stored $\left(4{ }^{\circ} \mathrm{C}\right)$ protected from light for further analysis. All standards and reagents used were acquired from common sources as previously described (Francisco et al., 2018).

\subsection{Proximate analysis and chemical characterization of Spirulina platensis}

\subsubsection{Nutritional composition}

Proximate analysis (proteins, lipids, carbohydrates and ashes) was performed following official methods (AOAC, 2016): protein content by macro-Kjeldahl method $(\mathrm{N} \times 6.25)$; lipid content by Soxhlet extraction with petroleum ether; ash content by incineration at $550 \pm 15^{\circ} \mathrm{C}$. Results were presented in $\mathrm{g} / 100 \mathrm{~g} \mathrm{dw}$ in all cases. Carbohydrates were calculated as the difference of the sum of protein, lipid and ash content to $100 \mathrm{~g} \mathrm{dw}$. Energy was calculated according to the Atwater system following the equation: energy $=4 \times(\mathrm{g}$ protein $+\mathrm{g}$ carbohydrate) $+9 \times$ ( $\mathrm{g}$ fat), and expressed in $\mathrm{kcal} / 100 \mathrm{~g} \mathrm{dw}$ (Manzi, Marconi, Aguzzi, \& Pizzoferrato, 2004).

\subsubsection{Chemical composition}

Organic acids. Organic acids were determined using a Shimadzu 20A series ultra-fast liquid chromatograph (Shimadzu Coperation, Kyoto, Japan) (Barros et al., 2013). Compounds were separated in a SphereClone (Phenomenex, Torrance, CA, USA) reverse phase $\mathrm{C}_{18}$ column $\left(5 \mu \mathrm{m}, 250 \mathrm{~mm} \times 4.6 \mathrm{~mm}\right.$ i.d) at $35^{\circ} \mathrm{C}$. After being eluted ( $3.6 \mathrm{mM}$ sulphuric acid solution, at $0.8 \mathrm{~mL} / \mathrm{min}$ ) compounds were analysed by diode array detection at $215 \mathrm{~nm}$ ( $245 \mathrm{~nm}$ for ascorbic acid). Quantification was based in calibration curves obtained from commercial standards (ascorbic acid, citric acid, malic acid, oxalic acid, and quinic acid). Results were expressed in $\mathrm{mg} / 100 \mathrm{~g} \mathrm{dw}$.

Fatty acids. After performing a transesterification step according to Barros et al. (2013), the resulting fatty acid methyl esters were profiled using a DANI 1000 gas chromatographer (GC) equipped with a split/ splitless injector $\left(1: 40,250^{\circ} \mathrm{C}\right)$, a flame ionization detector (FID at $260{ }^{\circ} \mathrm{C}$ ), and a $50 \%$ cyanopropyl-methyl-50\% phenylmethylpolysiloxane column $\left(30 \mathrm{~m} \times 0.32 \mathrm{~mm}\right.$ i.d. $\left.\times 0.25 \mu \mathrm{m} \mathrm{d}_{\mathrm{f}}\right)$ (Macherey-Nagel, Düren, Germany). Hydrogen was used as the carrier gas $(4.0 \mathrm{~mL} / \mathrm{min}$, $0.61 \mathrm{bar}, 50^{\circ} \mathrm{C}$ ) and compounds were identified by comparing their relative retention times with those of a FAME standards mixture. Results are expressed as relative percentage.

Tocopherols. Tocopherols were determined by high performance liquid chromatography (Knauer, Smartline system 1000, Berlin, Germany) using a fluorescence (excitation: $290 \mathrm{~nm}$; emission: $330 \mathrm{~nm}$ ) detector (FP-2020; Jasco, Easton, USA) (Barros et al., 2013). A normalphase Polyamide II column $(5 \mu \mathrm{m}, 250 \mathrm{~mm} \times 4.6 \mathrm{~mm}$ i.d., YMC, Waters, Lisbon, Portugal) was used operating at $35^{\circ} \mathrm{C}$. After elution (nhexane:ethyl acetate $70: 30, v / v, 1 \mathrm{~mL} / \mathrm{min}$ ), compounds were identified based on commercial standards and quantified (fluorescence signal) by the IS (tocol) method ( $\alpha$-, $\beta$-, $\gamma$-, and $\delta$-tocopherol calibration curves were used). Results were expressed as $\mu \mathrm{g} / 100 \mathrm{~g} \mathrm{dw}$.

Phycocyanin. Phycocyanins were extracted by the freezing and thawing method as described by Saran, Puri, Jasuja, and Sharma (2016), with some modifications. Different solvents were tested (distilled water, acetate buffer $0.1 \mathrm{M} \mathrm{pH} 6.0$; phosphate buffer $0.1 \mathrm{M} \mathrm{pH} \mathrm{7.0}$ and ethanol:water mixture 30:70 v/v). Three cycles were performed: freezing at $-20^{\circ} \mathrm{C}(1 \mathrm{~h})$ and thawing at room temperature (first cycle: $15 \mathrm{~min}$; second cycle: $30 \mathrm{~min}$; last cycle: $45 \mathrm{~min}$ ). After the thawing cycles, samples were centrifuged $(6000 \mathrm{rpm}, 15 \mathrm{~min})$ and the phycocyanin content calculated as (results in $\mathrm{mg} / \mathrm{mL})$ : $\mathrm{PC}=\left(\mathrm{Abs}_{615}-\right.$ 0.474Abs $\mathrm{Ab52}_{2}$ /5.43) (Bennett \& Bogorad, 1973). The purity of the extracted phycocyanin was determined by the $\mathrm{Abs}_{615} / \mathrm{Abs}_{280}$ ratio $\left(\mathrm{Abs}_{615}\right.$ : phycocyanin concentration; $\mathrm{Abs}_{280}$ : total protein concentration). Extraction yield was calculated as: $\mathrm{YP}=(\mathrm{PC} \times \mathrm{V} / \mathrm{S})$, where $\mathrm{PC}$ is the phycocyanin concentration, $\mathrm{V}$ the solvent volume and $\mathrm{S}$ the initial weight of spirulina.

\subsection{Microencapsulation of Spirulina platensis}

\subsubsection{Spray-drying microencapsulation process}

The microencapsulation process of spirulina was carried out using maltodextrin (MD) or maltodextrin cross-linked with citric acid as encapsulating materials, named SM and SMA samples respectively. The crosslinking reaction involves the reaction of hydroxyl groups from maltodextrin with carboxylic groups from citric acid (esterification reaction), and it was performed by spray drying process, according to the methodology developed by Francisco et al. (2018). A blank of SMA sample was also prepared (MA) consisting of MD crosslinked with citric acid, but without $S$. platensis. The used maltodextrin/S. platensis ratio was 1:1 (w/w). Briefly, for SM (maltodextrin/S. platensis), $15.75 \mathrm{~g}$ of $S$. platensis were dissolved in $150 \mathrm{~mL}$ of distilled water and added with $15.75 \mathrm{~g}$ of maltodextrin. For SMA (maltodextrin/S. platensis/citric acid), the previous mixture was added to $1.58 \mathrm{~g}$ of citric acid. These solutions were prepared just before the atomization. The used equipment was a Mini Spray Dryer B-290 Büchi (Flawil, Switzerland) set in the normal operation mode (nozzle diameter: $0.7 \mathrm{~mm}$; atomized volume: $150 \mathrm{~mL}$; 
solids content $<33 \%$ ). The equipment conditions were: inlet temperature $170{ }^{\circ} \mathrm{C}$, outlet temperature $95^{\circ} \mathrm{C}$, aspiration $90 \%$ and pump $20 \%(6 \mathrm{~mL} / \mathrm{min})$. The obtained samples were collected and kept in containers protected from light $\left(4^{\circ} \mathrm{C}\right)$ until further analysis. The overall yield was estimated as the ratio between the weight of recovered microspheres (dry basis) and the weight of atomized materials (dry basis) (maltodextrin, S. platensis and citric acid, when applied).

\subsubsection{Characterization of the microencapsulated samples}

Thermogravimetric analysis (TGA). TGA was performed on a NETZSCH equipment (TG 209 F3 Tarsus, Selb, Germany) (Francisco et al., 2018). The base materials (maltodextrin, citric acid and $S$. platensis) and the produced microspheres (SM, SMA and MA) were heated $\left(30{ }^{\circ} \mathrm{C}\right.$ to $600{ }^{\circ} \mathrm{C}$, at $10^{\circ} \mathrm{C} / \mathrm{min}$ ) in alumina crucibles $(6-8 \mathrm{mg}$ ), under a nitrogen flow.

Infrared Fourier Transform Spectroscopy (FTIR). FTIR spectra of the base materials (S. platensis and maltodextrin), and the microspheres (SM, SMA and MA), were acquired in a MB300 (ABB, Zurich, Switzerland) apparatus in transmittance mode. Samples $(1 \% \mathrm{w} / \mathrm{w})$ were dispersed in $\mathrm{KBr}$ and pelletized prior to analysis. Due to the hygroscopic nature of citric acid, and the difficulty to produce suitable $\mathrm{KBr}$ pellets, ATR mode was used for this sample. The following parameters were set: $32 \mathrm{scans} / \mathrm{min}$, with a resolution of $16 \mathrm{~cm}^{-1}$ within the spectral range of $4000-550 \mathrm{~cm}^{-1}$. Spectra were obtained with Horizon MB software version 3.4.

Particle Size. Size distributions of the produced microspheres were determined in a Malvern Mastersizer 3000 equipped with a Hydro MV dispersion unit (Malvern, UK), using ethanol as the dispersing medium. Data acquisition and treatment were performed with the Mastersizer Software Version 3.10. The size distribution in volume and number were determined, as well as their respective average values.

Morphological Analysis. Morphological characterization of S. platensis and produced microspheres was done by optical (OM) and scanning electron microscopy (SEM). The used optical microscope was a NiU Nikon (Nikon Instruments Europe, Amsterdam, The Netherlands) equipped with a digital camera. The scanning electron microscope was a Phenom Pro (Thermo Fisher Scientific, Dillenburgstraat, The Netherlands).

\subsection{Bioactive and cytotoxic properties of free and microencapsulated spirulina platensis}

\subsubsection{Antioxidant activity}

The free form of $S$. platensis (S), microencapsulated samples (SM and SMA), and encapsulation materials (MD and MA) were dissolved in water $(50 \mathrm{mg} / \mathrm{mL})$ and diluted successively. In the case of free spirulina, samples were homogenized by vortexing to achieve the best possible homogenization of the sample, since they were not equally soluble as the microencapsulated forms. This procedure was followed for all assays using water as solvent.

DPPH radical-scavenging activity was evaluated by using a microplate reader and calculated with the formula: [( $\left.\mathrm{A}_{\mathrm{DPPH}}-\mathrm{A}_{\mathrm{S}}\right)$ / $\left.A_{D P P H}\right] \times 100$, where $A_{S}$ is the absorbance of the sample at $515 \mathrm{~nm}$ and $A_{\text {DPPH }}$ is the absorbance of the DPPH solution. Reducing power was determined by the capacity to convert $\mathrm{Fe}^{3+}$ into $\mathrm{Fe}^{2+}$, by using a microplate reader and measuring the absorbance at $690 \mathrm{~nm}$. Inhibition of $\beta$-carotene bleaching was evaluated by $\beta$-carotene/linoleate assay and expressed as percentage of inhibition of $\beta$-carotene bleaching using the formula: $\left[\left(\mathrm{A}_{\mathrm{T} 120} / \mathrm{A}_{\mathrm{T} 0}\right)\right] \times 100$, where $\mathrm{A}_{\mathrm{T} 120}$ is the absorbance of the sample after $2 \mathrm{~h}$ of assay and $\mathrm{A}_{\text {To }}$ is the initial absorbance. DPPH radical-scavenging activity, reducing power and $\beta$-carotene/linoleate assay were performed according to Sarmento, Barros, Fernandes, Carvalho, and Ferreira (2015). Inhibition of oxidative haemolysis in erythrocytes obtained from sheep blood was evaluated by the inhibition haemolysis oxidative assay (OxHLIA) (Lockowandt et al., 2019). The results were expressed as the inhibitory concentration $\left(\mathrm{EC}_{50}\right.$ value, $\mathrm{mg}$ /
$\mathrm{mL}$ ) able to promote a haemolysis delay $(\Delta \mathrm{t})$ of $60 \mathrm{~min}$ and $120 \mathrm{~min}$ using the formula: $\left[\Delta \mathrm{t}=\mathrm{Ht}_{50}\right.$ (sample) $-\mathrm{Ht}_{50}$ (control)], where $\mathrm{Ht}_{50}$ is $50 \%$ haemolytic time ( $\mathrm{min}$ ) graphically obtained from the haemolysis curve of each sample concentration. For the remaining assays, results were expressed as $\mathrm{EC}_{50}$, corresponding to the extract concentrations providing $50 \%$ of antioxidant activity or 0.5 of absorbance, calculated from the graphs of antioxidant activity percentages (DPPH and $\beta$-carotene bleaching) or absorbance at $690 \mathrm{~nm}$ (reducing power assay) against extract concentrations.

\subsubsection{Anti-inflammatory activity}

The anti-inflammatory activity of the free form of S. platensis (S), the microencapsulated samples (SM and SMA), and the encapsulation materials (MD and MA) was performed according to Corrêa et al. (2015). Briefly, samples were dissolved at $8 \mathrm{mg} / \mathrm{mL}$ in water and the LPS-induced nitric oxide (NO) production by macrophage (RAW 264.7) cell lines was determined using the Griess Reagent Systm kit, with dexamethasone as a positive control. The NO production was determined by measuring the absorbance at $540 \mathrm{~nm}$ and comparison with the calibration curve $\mathrm{y}=0.007 \mathrm{x}+0.1328, R^{2}=0.9982$. Results were expressed in $\mathrm{EC}_{50}$ value $(\mu \mathrm{g} / \mathrm{mL})$, which correspond to the sample concentration providing $50 \%$ inhibition of NO production.

\subsubsection{Antibacterial activity}

Antibacterial evaluation was performed against four Gram-positive bacteria (methicillin-resistant Staphylococcus aureus - MRSA, methicillin-sensitive Staphylococcus aureus - MSSA, Enterococcus faecalis and Listeria monocytogenes) and five Gram-negative bacteria (Escherichia coli, Klebsiella pneumoniae, Morganella morganii, Proteus mirabilis e Pseudomonas aeruginosa). The free form of $S$. platensis (S), the microencapsulated samples (SM and SMA), and the encapsulation materials (MD and MA) were prepared by dissolving $100 \mathrm{mg}$ in $1 \mathrm{~mL}$ of culture medium (Muller Hinton Broth (MHB) or Tryptic Soy Broth (TSB) depending on the bacteria). Briefly, $190 \mu \mathrm{L}$ of the stock solution were added to the first well of the 96-well microplate and successive dilutions were carried out over the wells containing $90 \mu \mathrm{L}$ of medium. Afterwards, $10 \mu \mathrm{L}$ of inoculum $\left(1.5 \times 10^{8} \mathrm{CFU} / \mathrm{mL}\right)$ were added to all wells (concentrations range: of $0.156-20 \mathrm{mg} / \mathrm{mL}$ ). The minimal inhibitory concentration (MIC, $\mathrm{mg} / \mathrm{mL}$ ) was carried out by the microdilution method using INT colorimetric assay (Melgar et al., 2018). The minimal bactericidal concentration ( $\mathrm{MBC}, \mathrm{mg} / \mathrm{mL}$ ) was determined by sub-cultivation into microplates. Ampicillin and imipenem were used as positive controls to Gram-negative bacteria and vancomycin and ampicillin to the Gram-positive bacteria. MHB/TSB and bacteria were used as negative control.

\subsubsection{Cytotoxicity of Spirulina platensis in non-tumour liver cells primary culture}

Cytotoxicity evaluation was performed by the sulforhodamine B assay (SRB) with a porcine liver primary culture cell (PLP2) according to Abreu et al. (2011). The free forms of S. platensis (S), the microencapsulated samples (SM and SMA), and the encapsulation materials (MD and MA) were dissolved in water at $8 \mathrm{mg} / \mathrm{mL}$ followed by successive dilutions. PLP2 cells were treated for $48 \mathrm{~h}$ with the sample solutions and ellipticine was used as positive control. The results were expressed as $\mathrm{GI}_{50}$ values (sample concentration that inhibited $50 \%$ of the net cell growth) in $\mu \mathrm{g} / \mathrm{mL}$.

\subsection{Yogurts added with spirulina-based ingredients}

\subsubsection{Yogurts preparation}

Solid natural yogurts were purchased at a local store (Bragança, Portugal). The labelled nutritional composition per $100 \mathrm{~g}$ was: $75 \mathrm{kcal}$, $3.8 \mathrm{~g}$ of lipids (among which $2.4 \mathrm{~g}$ of saturated fatty acids), $4.7 \mathrm{~g}$ of sugars, $5 \mathrm{~g}$ of proteins, and $0.15 \mathrm{~g}$ of salt.

The quantity of $S$. platensis to be added into the yogurt was 
determined according to the Food and Drug Administration recommendations (Food \& Administration, 2002). For addition in foods, FDA indicates the range of $0.5-3 \mathrm{~g}$ of $S$. platensis per serving portion. Therefore, $1.5 \mathrm{~g}$ of $S$. platensis was added to each yogurt (150 g).

Four test groups $(150 \mathrm{~g}$ ) were set: control (YC: yogurt without $S$. platensis or microspheres); yogurt added with $1.5 \mathrm{~g}$ of $S$. platensis (YS); yogurt added with $3.0 \mathrm{~g}$ of SM microspheres (YSM); and yogurt added with $3.125 \mathrm{~g}$ of SMA microspheres (YSMA). The quantities of microspheres were chosen in order to include $1.5 \mathrm{~g}$ of $S$. platensis. The analysis was carried out after preparation ( 0 days), after four days ( 4 days), and seven days ( 7 days) of storage $\left(4^{\circ} \mathrm{C}\right)$.

\subsubsection{Nutritional and bioactive properties}

The nutritional value and energy determination were performed according to the procedures described in Section 2.2.1. For protein content, the conversion factor $\mathrm{N} \times 3.8$ was used as defined for this type of product. The fatty acids were determined according to the procedures described in 2.2.2.

Free sugars. Free sugars were determined with an HPLC with refractive index (IR) detection (Knauer Smartline 2300). The chromatographic separation was achieved with a Eurospher $100-5 \mathrm{NH}_{2}$ column $\left(4.6 \times 250 \mathrm{~mm}, 5 \mu \mathrm{m}\right.$, Knauer) operating at $30^{\circ} \mathrm{C}$ (Barros et al., 2013). The mobile phase was acetonitrile/deionized water, 70:30 $(v / v)$ at a flow rate of $1 \mathrm{~mL} / \mathrm{min}$. Sugars were identified by comparing the relative retention times with standards. Data were analyzed with Clarity 2.4 Software (DataApex, Podohradska, Czech Republic) and sugars' quantification was based in the internal standard (melezitose) method. Results were expressed in $\mathrm{g} / 100 \mathrm{~g} \mathrm{dw}$.

Bioactive properties. The antioxidant activity (DPPH and reducing power) of yogurts added with the prepared $S$. platensis-based ingredients were evaluated according to the methodologies detailed in 2.4.1.

\subsubsection{Evaluation of colour and $\mathrm{pH}$}

Colour evaluation of yogurt samples was performed using the equipment Konica Minolta CR-400 (Chiyoda, Tokyo, Japan) and data were further analysed with Spectra Magic Nx version CM-S200W 2.03.0006 software. $\mathrm{pH}$ was determined with the $\mathrm{pH}$ meter HI 99,161 (Hanna Intruments, Woonsocket, RI, USA) (Fernandes et al., 2018). All the analyses were done in triplicate.

\subsection{Statistical analysis}

All statistical tests were carried out at a 5\% significant level using IBM SPSS Statistics for Windows, version 22.0. (IBM Corp., Armonk, NY, USA). In each table, data were expressed as mean \pm standard deviation, maintaining the significant numbers allowed by the magnitude of the standard deviation.

The results obtained in the bioactivity evaluation of the free form of S. platensis (S), the microencapsulated samples (SM and SMA), and the encapsulation materials (MD and MA) were compared by performing an analysis of variance (ANOVA), followed by Tukey's test (homoscedastic distributions) or Tamhane's T2 test (heteroscedastic distributions). The fulfilment of one-way ANOVA requirements, i.e., the normal distribution of the residuals and the homogeneity of variance, was tested by Shapiro Wilk's and Levene's tests, respectively.

An analysis of variance (ANOVA) with type III sums of squares was performed using the general linear model (GLM) procedure to compare differences in the evaluated parameters of prepared yogurts. The dependent variables were analysed using 2-way ANOVA with the factors "yogurt formulation" (YF) and "storage time" (ST). When a statistically significant interaction among the two factors was found, their effect was evaluated by the estimated marginal means plots for all levels of each factor. On the contrary, cases with no significant interaction were compared using Tukey's multiple comparison test, after verifying the homogeneity of variances through Levene's test.
In addition, a linear discriminant analysis (LDA) was used to characterize the overall YF effect. A stepwise technique was applied, considering the Wilks' $\Lambda$ test with the usual probabilities of $F$ (3.84 to add variables and 2.71 to remove variables). This procedure is based in sequential forward selection and backward elimination steps, which require verifying the significance of all previously selected variables before including a new one (Zielinski et al., 2014). The main purpose was estimating the relationship between the single categorical dependent variables (yogurt formulations) and the quantitative independent variables (results obtained in the laboratorial assays). The LDA outputs allowed determining which independent variables contributed more to the differences in the average score profiles of different YF. A leavingone-out cross validation procedure was carried out to assess the model performance.

\section{Results and discussion}

\subsection{Nutritional and chemical composition of Spirulina platensis}

The Spirulina platensis biomass was characterized for nutritional composition and energetic value. Spirulina is known for its high protein content, which was also confirmed in this work $(75.6 \pm 0.3 \mathrm{~g} / 100 \mathrm{~g}$ $\mathrm{dw})$ and high carbohydrate content $(17.5 \pm 0.3 \mathrm{~g} / 100 \mathrm{~g} \mathrm{dw})$. This microalga also revealed a high ash content $(6.2 \pm 0.1 \mathrm{~g} / 100 \mathrm{~g} \mathrm{dw})$, fact associated with its richness in minerals; in turn, fat content was low $(0.65 \pm 0.04 \mathrm{~g} / 100 \mathrm{~g} \mathrm{dw})$. This nutritional composition corresponded to an energetic value of $378 \pm 1 \mathrm{kcal} / 100 \mathrm{~g} \mathrm{dw}$. In general, these results corroborate previous reports on the nutritional composition of Spirulina platensis (Agustini, Suzery, Sutrisnanto, Maruf, \& Hadiyanto, 2015; Sharoba, 2014), and are in accordance with the ones reported in the commercial label.

The major organic acid found in $S$. platensis was quinic acid (792 mg/100 g dw), which has been associated to anti-inflammatory effects (Jang et al., 2017). Oxalic acid was also found, but only in trace levels (below the LOQ).

In what concerns fatty acids profile, a total of 22 individual compounds were identified (Table 1). Polyunsaturated fatty acids were the major group (47.8\%), particularly due to $\gamma$-linolenic (27.6\%) and linoleic $(17.9 \%)$ acids. On the other hand, palmitic acid was the major saturated fatty acid (33.3\%). This profile is in agreement with previous reports (Sharoba, 2014). Nevertheless, the environmental conditions (e.g., temperature and light incidence) seem to influence the fatty acids profile, since $S$. platensis samples collected from Natron Lake located in Chad, showed lower percentages of $\gamma$-linolenic acid (12.9\%) and higher percentages of palmitic acid (46.1\%) (Mühling, Belay, \& Whitton, 2005).

In addition, three tocopherol isoforms were found in S. platensis ( $\alpha$-, $\beta$-, and $\delta$-tocopherol), with $\alpha$-tocopherol (388 $\mu \mathrm{g} / 100 \mathrm{~g} \mathrm{dw})$ and $\delta$-tocopherol $(139 \mu \mathrm{g} / 100 \mathrm{~g} \mathrm{dw})$ as the most abundant (Table 1). However, Gómez-Coronado, Ibañez, Rupérez, and Barbas (2004) identified and quantified a higher content of $\alpha$-tocopherol vitamer $(1300 \mu \mathrm{g} / 100 \mathrm{~g}$ $\mathrm{dw}$ ) in a $S$. platensis sample purchased from Spain. The differences found may be due to the applied extraction methods, since tocopherols are easily oxidized by light, heat, alkaline conditions and free radicals.

Phycocyanin is an accessory pigment of chlorophyll and belongs to the phycobiliprotein family. It is soluble in water and can be easily extracted from S. platensis (Chaiklahan, Chirasuwan, \& Bunnag, 2012), usually by the freezing/thawing method (forms ice crystals that cause cell disruption, facilitating the pigments' release), employing different solvents (Abalde, 1998; Kumar, Dhar, Pabbi, Kumar, \& Walia, 2014; Soni, Kalavadia, Trivedi, \& Madamwar, 2006). In this work, water was the solvent that allowed to extract the highest amount of phycocyanin $(1.44 \mathrm{mg} / \mathrm{mL}$, Table 1$)$, which was significantly higher than the concentrations obtained with acetate buffer, phosphate buffer, and ethanol (Table A1, supplementary material), and also higher than the concentrations obtained in similar studies (Paliwal, Bhayani, Maurya, \& 
Table 1

Fatty acids profile (relative percentage), tocopherols ( $\mu \mathrm{g} / 100 \mathrm{~g} \mathrm{dw}$ ) and phycocyanin of Spirulina plantensis. Values are indicated as mean \pm standard deviation.

\begin{tabular}{|c|c|c|c|}
\hline Fatty acids & S. platensis & Fatty acids & S. platensis \\
\hline C6:0 & $0.08 \pm 0.01$ & C18:3n3 & $0.36 \pm 0.01$ \\
\hline C8:0 & $0.14 \pm 0.01$ & C20:0 & $0.26 \pm 0.02$ \\
\hline C10:0 & $0.21 \pm 0.01$ & C20:1 & $0.11 \pm 0.01$ \\
\hline $\mathrm{C} 12: 0$ & $1.76 \pm 0.07$ & C20:2 & $0.11 \pm 0.01$ \\
\hline C14:0 & $1.00 \pm 0.05$ & C20:3n6 & $0.84 \pm 0.06$ \\
\hline C15:0 & $1.01 \pm 0.02$ & C20:4n6 & $0.48 \pm 0.04$ \\
\hline C16:0 & $33.3 \pm 0.5$ & C22:0 & $0.93 \pm 0.01$ \\
\hline C16:1 & $3.24 \pm 0.03$ & $\mathrm{C} 22: 6 \mathrm{n} 3$ & $0.55 \pm 0.04$ \\
\hline $\mathrm{C} 17: 0$ & $1.07 \pm 0.07$ & $\mathrm{C} 24: 0$ & $0.09 \pm 0.01$ \\
\hline C18:0 & $5.77 \pm 0.08$ & SFA & $45.6 \pm 0.5$ \\
\hline C18:1n9 & $3.3 \pm 0.2$ & MUFA & $6.6 \pm 0.1$ \\
\hline C18:2n6 & $17.9 \pm 0.1$ & PUFA & $47.8 \pm 0.4$ \\
\hline C18:3n6 & $27.6 \pm 0.3$ & & \\
\hline Tocopherols & S. platensis & Phycocianin & $\begin{array}{l}\text { S. platensis extraction } \\
\text { (distilled water) }\end{array}$ \\
\hline$\alpha$-tocopherol & $388 \pm 8$ & $\begin{array}{l}\text { Concentration (mg/ } \\
\mathrm{mL})\end{array}$ & $1.44 \pm 0.01$ \\
\hline$\beta$-tocopherol & $32 \pm 1$ & Yield (g/100 g dw) & $1.82 \pm 0.01$ \\
\hline$\delta$-tocopherol & $139 \pm 5$ & Purity & $0.330 \pm 0.002$ \\
\hline Total & $559 \pm 14$ & & \\
\hline
\end{tabular}

The results of fatty acids are expressed in relative percentage

the results of tocopherols are expressed in dry weight (dw) basis. Caproic acid (C6:0)

Caprylic acid (C8:0)

Capric acid (C10:0)

Lauric acid (C12:0)

Myristic acid (C14:0)

Pentadecanoic acid (C15:0)

Palmitic acid (C16:0)

Palmitoleic acid (C16:1)

Heptadecanoic acid (C17:0)

Stearic acid (C18:0)

Oleic acid (C18:1n9)

Linoleic acid (C18:2n6c)

$\alpha$-Linolenic acid (C18:3n3)

Arachidic acid (C20:0)

Behenic acid (C22:0)

Tricosanoic acid (C23:0)

Lignoceric acid (C24:0) and Nervonic acid (C24:1). SFA

total saturated fatty acids

MUFA

total monounsaturated fatty acids

PUFA

total polyunsaturated fatty acids.

Mishra, 2015). In either case, there is the possibility of losing phycocyanin during the drying and heating processes (ilter et al., 2018).

\subsection{Microencapsulation process of Spirulina platensis}

The microencapsulation process yield was 66\% for SM (S. platensis encapsulated in maltodextrin MD) microspheres and $75 \%$ for SMA ( $S$. platensis encapsulated in MD crosslinked with citric acid). Studies carried out by Ribeiro et al. (2015), dealing with the microencapsulation of mushroom hydroalcoholic extracts using maltodextrin as the encapsulating material, reported lower yields (around 50\%). In fact, these values can be low, usually lower than $50 \%$ for small-scale assays, as in the case of the present study (atomized volume of $150 \mathrm{~mL}$ ). However, these values tend to increase when evolving to continuous (industrial) processes. In this regard, the obtained values were quite significant. In this work, considering the homogeneity of the spray-dried solution and that the material showed to be resistant to the conditions of the spraydrying process, the microencapsulation efficiency has been assumed to be $100 \%$ and the load (measure of the spirulina content in the microspheres) equivalent to the theoretical values. Thus, the microspheres load was $0.50 \mathrm{~g} \mathrm{~S}$. platensis/g microspheres for SM and $0.48 \mathrm{~g} \mathrm{~S}$. platensis/g microspheres for SMA.

TGA/DTG analysis was performed to check the thermal degradation and the weight loss of the base materials and produced samples. Fig. A1 (supplementary material) reported the thermogravimetric analysis of base materials (S. platensis (S), maltodextrin (MD) and citric acid (CA)). The $S$. platensis degradation profile shows an initial degradation at $100{ }^{\circ} \mathrm{C}(5.49 \%)$ corresponding to the presence of water in the material. The microalga degrades in the range of $163^{\circ} \mathrm{C}$ to $464^{\circ} \mathrm{C}$, with the maximum degradation temperature at $304^{\circ} \mathrm{C}$. The obtained final residue at $600{ }^{\circ} \mathrm{C}$ was $27.65 \%$. Three degradation stages can be described: the first one $\left(163-158^{\circ} \mathrm{C}\right)$ corresponds to carbohydrates and proteins degradation (Bach \& Chen, 2017; Batista, Gouveia, Bandarra, Franco, \& Raymundo, 2013); the second one $\left(358-464^{\circ} \mathrm{C}\right)$ is related to lipids loss as described by Li, Srivatsa, Batchelor, and Bhattacharya (2017) for Tetraselmis suecica microalgae; the third step of degradation (above $463^{\circ} \mathrm{C}$ ) is related to the degradation of the more thermally resistant compounds of microalgae.

Citric acid shows a thermal degradation profile starting at $160{ }^{\circ} \mathrm{C}$ with a maximum degradation temperature of $199^{\circ} \mathrm{C}$. The final residue was $7.36 \%$. In the case of maltodextrin, the region corresponding to the water loss was detected along a wide range of temperatures. According to some authors, this feature is a characteristic of hydrophilic polymers, where the degradation is sub-divided in free, freezing bound and nonfreezing bound water. Free water does not interact with polymer molecules, behaving like pure water. Freezing bound corresponds to an intermediate state, whereas non-freezing bound (known as bound water) interacts with polymeric molecules forming hydrogen bonds (Pathak, Yun, Lee, \& Paeng, 2010; Russo, Malinconico, \& Santagata, 2007). For maltodextrin, the free water corresponds to the degradation until $100{ }^{\circ} \mathrm{C}$, while freezing and non-freezing bound water is detected in the range of $100-200^{\circ} \mathrm{C}$. The maltodextrin initial degradation $\left(211-277^{\circ} \mathrm{C} ; 6.25 \%\right)$ was related to the degradation of lower molecular weight fractions. The main degradation occurred in the range of $277-408{ }^{\circ} \mathrm{C}$ with a maximum degradation temperature at $315^{\circ} \mathrm{C}$. The final residue was $14.58 \%$. Summarizing, the base materials are resistant to the conditions used in the spray-drying process, thus validating the estimative made for microencapsulation efficiency (100\%).

Fig. $1 \mathrm{~A}$ and $\mathrm{B}$ shows the resulting thermograms of SM and SMA microspheres. A first weight loss observed for the SM sample $\left(100-144{ }^{\circ} \mathrm{C}\right)$ corresponds to the water loss. Then, two stages of degradation occur. The first stage occurs in the range of $144-242^{\circ} \mathrm{C}$ $(13.80 \%)$ and the second one in the interval $242-304{ }^{\circ} \mathrm{C}(22.00 \%)$. The degradation profile of SM is slower than the one of the base materials starting at lower temperatures, which denotes the characteristics of the material's mixture (maltodextrin and $S$. platensis). The final residue for SM was $25.10 \%$. SMA sample shows a thermal degradation starting in the range of $100-145^{\circ} \mathrm{C}$ (water loss). The maximum temperature of degradation was $306^{\circ} \mathrm{C}$ and the final residue $25.49 \%$.

Comparing the thermograms of SM and SMA, the microspheres present similar characteristics for the temperature degradation range (initial temperature and final temperature), as well as for the final residue. Comparatively to SMA, the SM sample originates two more defined degradation stages, being the first one less pronounced. In addition, the degradation profile of SMA is displaced to higher temperatures. This may be associated to the effective occurrence of crosslinking, which promotes better material's homogeneity and protective effect (Azeredo \& Waldron, 2016).

FTIR analysis of the base materials (maltodextrin, $S$. platensis, and citric acid), and of the microspheres (SM, SMA and MA) is represented in Fig. 2. The $S$. platensis spectrum showed the presence of a wide band centred at $3302 \mathrm{~cm}^{-1}$ related to $\mathrm{O}-\mathrm{H}$ and N-H groups, and a band in the region $3000-2750 \mathrm{~cm}^{-1}$ assigned to the presence of the $\mathrm{C}-\mathrm{H}$ groups. The contribution of the carbonyl groups at $1750 \mathrm{~cm}^{-1}$ (esters) and at 

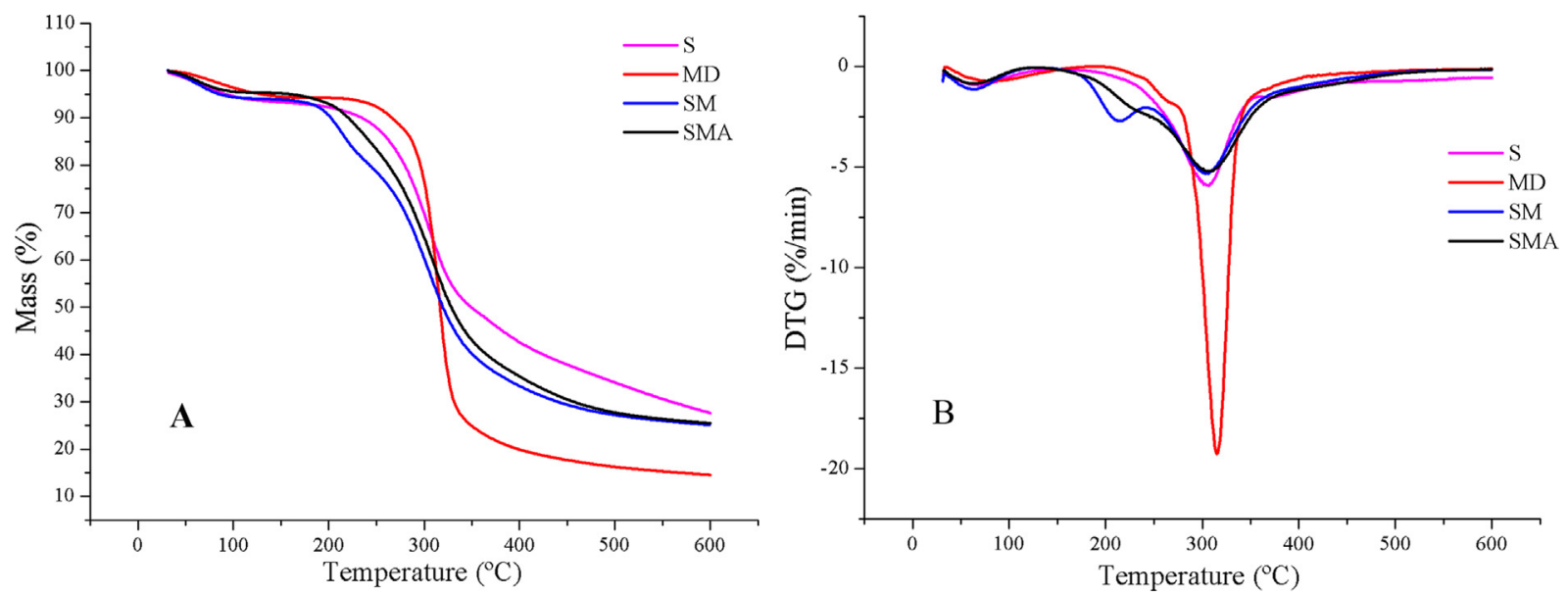

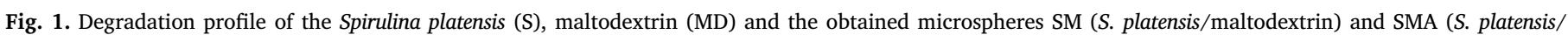
maltodextrin crosslinked with citric acid). Mass loss (A) and DTG (B).

$1659 \mathrm{~cm}^{-1}$ (amides) was also observed. Additionally, the vibration at $1543 \mathrm{~cm}^{-1}$ was associated to the presence of N-H groups.

The region from 1500 to $500 \mathrm{~cm}^{-1}$ corresponds to the overlapping of bands, namely the $\mathrm{C}-\mathrm{H}$ band deformation and $\mathrm{C}-\mathrm{O}$ stretching. For the maltodextrin spectrum, the wide band centred at $3402 \mathrm{~cm}^{-1}$ was attributed to the hydroxyl groups. Additionally, there are contributions of $\mathrm{C}$ - $\mathrm{H}$ groups in the range of $3000-2750 \mathrm{~cm}^{-1}$ and contributions of diverse bands in the region $1500-500 \mathrm{~cm}^{-1}$. The band at $1643 \mathrm{~cm}^{-1}$ corresponds to water bound to maltodextrin (a typical feature of polysaccharides).

For citric acid, the main characteristics are the existence of free $\mathrm{OH}$ $\left(3495 \mathrm{~cm}^{-1}\right.$ ) and associated (hydrogen bonded) $\mathrm{OH}$ (region centred on $3279 \mathrm{~cm}^{-1}$ ). In addition, it presents two peaks related to carbonyl groups (1744 and $1697 \mathrm{~cm}^{-1}$ ). The disappearance of these peaks is related to the occurrence of esterification (Castro-Cabado, Casado, \& San Román, 2016a).

The microspheres spectra suggest the contribution of the base materials, namely of $S$. platensis and maltodextrin. As an example, the vibration at $1659 \mathrm{~cm}^{-1}$, attributed to the carbonyl groups, and the one located at $1543 \mathrm{~cm}^{-1}$, corresponding to the $\mathrm{N}-\mathrm{H}$ groups in spirulina, are present in SM and SMA microsphere's spectra. Additionally, it is possible to verify the occurrence of the esterification reaction by the disappearance of the two characteristics bands of citric acid (1744 and $1697 \mathrm{~cm}^{-1}$ ) and the appearance of an intermediate vibration at $1728 \mathrm{~cm}^{-1}$. This feature is particularly visible in the MA spectrum. The close vibration at $1643 \mathrm{~cm}^{-1}$, was associated to the bound water, as previously described for maltodextrin. For SMA spectrum, the band identified at $1728 \mathrm{~cm}^{-1}$ was not so visible due to the overlapping with the vibrations typical of the spirulina spectrum (shoulder at $1750 \mathrm{~cm}^{-1}$ ). This aspect is also visible in the SM spectrum. It was also observed an intense contribution (for SMA sample) in the region associated to the ester C-O stretching $\left(1500-500 \mathrm{~cm}^{-1}\right.$ ) (red ellipse in Fig. 2), in comparison with the SM sample. This feature is also visible in the MA spectrum.

The obtained microspheres have a size distribution in volume varying from 3.11 to $21.7 \mu \mathrm{m}$ (average size of $10.78 \mu \mathrm{m}$ for SM, 11.14 for SMA and 7.94 for MA). The corresponding distribution in number comprised sizes ranging from $1.09 \mu \mathrm{m}$ to $6.25 \mu \mathrm{m}$ (average size of $2.90 \mu \mathrm{m}$ for SM, 2.89 for SMA and $2.19 \mu \mathrm{m}$ for MA). The size distribution in number reveals similar distributions for the three samples (Fig. A2, supplementary material). In what concerns the SM and SMA samples, similar size distributions in volume were observed, while for MA sample a shift towards lower sizes was observed.

The morphological analysis of $S$. platensis and of the produced microspheres was performed by optical and scanning electron microscopy. It can be observed (Fig. 3A) that $S$. platensis shows a spiral structure and a fragmented pattern (resulting from drying). In addition, SMA microspheres are more uniform than SM. The MA microspheres have a spherical structure, while SM and SMA had, in some cases, a spiral conformation, which suggests spirulina clusters covered with maltodextrin. This was corroborated by SEM analysis (Fig. 3A), where it was also possible to distinguish, for both SM and SMA, the microalga structure covered by the encapsulating materials and microspheres formed by clusters of these structures. In any case, the most prominent morphology is the spherical one.

\subsection{Bioactive properties of free and microencapsulated spirulina}

The free form of $S$. platensis (S), the obtained microspheres (SM and SMA), and encapsulation materials (MD and MA) were submitted to several bioactivity assays, such as antioxidant, anti-inflammatory and antibacterial activities, as also their cytotoxic effects (Table 2).

In what concerns the antioxidant activity, the free form of $S$. platensis showed the highest DPPH scavenging activity and reducing power when compared to microspheres (SM: 50\% S. platensis and SMA: $48 \% S$. platensis), with SMA showing better antioxidant activity than SM. In the case of MD and MA microspheres, no antioxidant activity was observed, even at the maximum tested concentration $(50 \mathrm{mg} / \mathrm{mL})$.

The antioxidant power of $S$. platensis may be due to the presence of bioactive compounds such as $\alpha$-tocopherol and phycocyanin that, in addition, can present synergist antioxidant properties, as reported by Santiago-Morales, Trujillo-Valle, and Márquez-Rocha (2018). Although other forms of tocopherols ( $\beta$ - and $\delta$-tocopherol) are found in Spirulina, the antioxidant activity is mostly related with the presence of $\alpha$-tocopherol, whereas $\beta$ - and $\delta$-tocopherols are mainly associated with the anti-inflammatory effects (Azzi, 2018).

Paliwal et al. (2015), who accessed the antioxidant activity of aqueous and methanolic extracts of Spirulina sp. by the DPPH method, highlight the high content of phycocyanin in these extracts. Similarly to this study, Shalaby and Shanab (2013) also related the high antioxidant power of the $S$. platensis aqueous extracts with the high content of phycobiliproteins. This is the case of the present work, where phycocyanin $(1.82 \mathrm{mg} / 100 \mathrm{~g} \mathrm{dw})$ was present at higher concentration than tocopherol $(559 \mu \mathrm{g} / 100 \mathrm{~g} \mathrm{dw} ; 388 \mu \mathrm{g} / 100 \mathrm{~g} \mathrm{dw}$ for $\alpha$-tocopherol), putting in evidence the role of phycocyanin in the antioxidant activity.

In the $\beta$-carotene/linoleate method, the SMA sample showed the highest antioxidant activity compared to S and SM. It is important to note that the MA sample (control) also showed antioxidant activity, pointed out the contribution of the crosslinking reaction for this result.

Regarding the OxHLIA methodology, where the sample concentration to protect $50 \%$ of the erythrocyte population from the haemolytic action caused by the used oxidizing agent $\left(\mathrm{EC}_{50}\right)$, for 60 and $120 \mathrm{~min}$ 


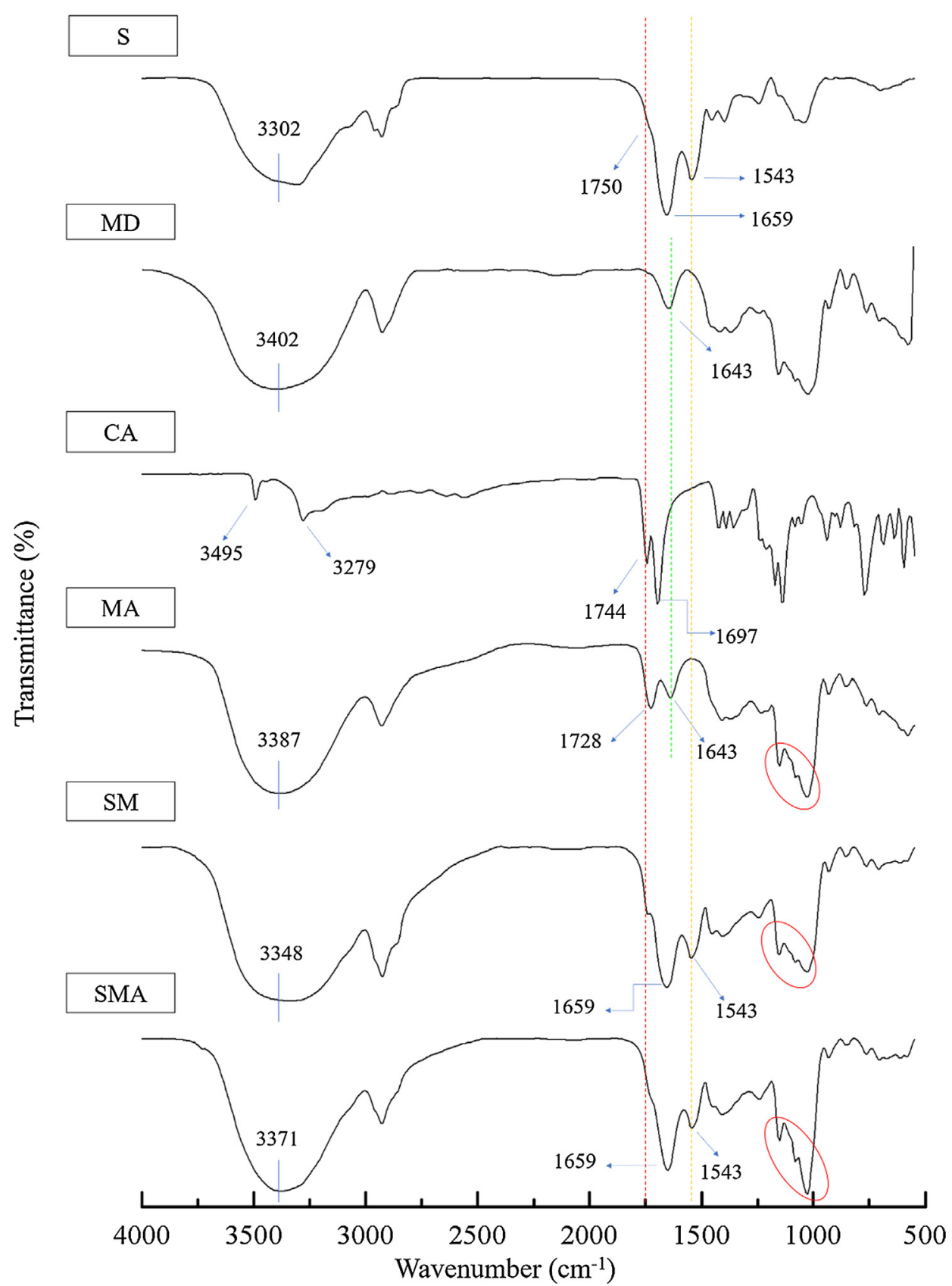

Fig. 2. FTIR spectra of base materials Spirulina platensis (S), maltodextrin (MD) and citric acid (CA), and microspheres MA (without S. platensis), SM (S. platensis/ maltodextrin) and SMA (S. platensis/maltodextrin crosslinked with citric acid).

are determined, indicated that all samples have significant differences for in the $\mathrm{EC}_{50}$ values (at 60 and $120 \mathrm{~min}$ ). The free form of S. platensis showed the highest antioxidant activity, with $\mathrm{EC}_{50}$ values of $0.26 \pm 0.01$ and $0.57 \pm 0.01 \mathrm{mg} / \mathrm{mL}$ at 60 and $120 \mathrm{~min}$, respectively. Subsequently, SM $(50 \% \mathrm{~S}$. platensis) showed the second highest antioxidant potential, followed by SMA (48\% S. platensis). However, the antihaemolytic capacity of the tested samples was lower than the used positive control, Trolox $(0.022 \pm 0.001$ and $0.044 \pm 0.001 \mathrm{mg} / \mathrm{mL}$, at 60 and $120 \mathrm{~min}$, respectively).

In the case of anti-inflammatory activity (Table 2), the best results were obtained with SMA, whilst the worst were registered for MD, and all tested samples showed significant differences in $\mathrm{EC}_{50}$ values. Studies by Chen, Liu, Yang, Hwang, Chan, and Lee (2012) also showed antiinflammatory effects of the $S$. platensis aqueous extract, and of the phycocyanin pigment in LPS-stimulated microglia cells (BV-2). In another study, Al-qahtani and Binobead (2018) analysed the anti- inflammatory effect in vivo, using the induction of hepatotoxicity in mice and inclusion of different concentrations of $S$. platensis in the diet during one week, observing that the ingestion of $S$. platensis led to a decrease in pro-inflammatory cytokines.

None of the assayed samples showed cytotoxicity (Table 2) up to the maximum assayed concentration $(400 \mu \mathrm{g} / \mathrm{mL})$, indicating their possible use in food applications. It is also important to note that, even in the case of maltodextrin crosslinked with citric acid (SMA and MA samples), there was no formation of toxic compounds.

Many studies have been conducted in recent years to explore natural products as antimicrobial agents to combat microbial resistance. In this way, S, SM, SMA, MD and MA were evaluated for their antibacterial activity against Gram-negative and Gram-positive species.

In what concerns Gram-negative bacteria, K. pneumoniae turned out to be the most sensitive species (the MIC values obtained with the assayed samples were similar to those observed with ampicillin), while $P$. 
A

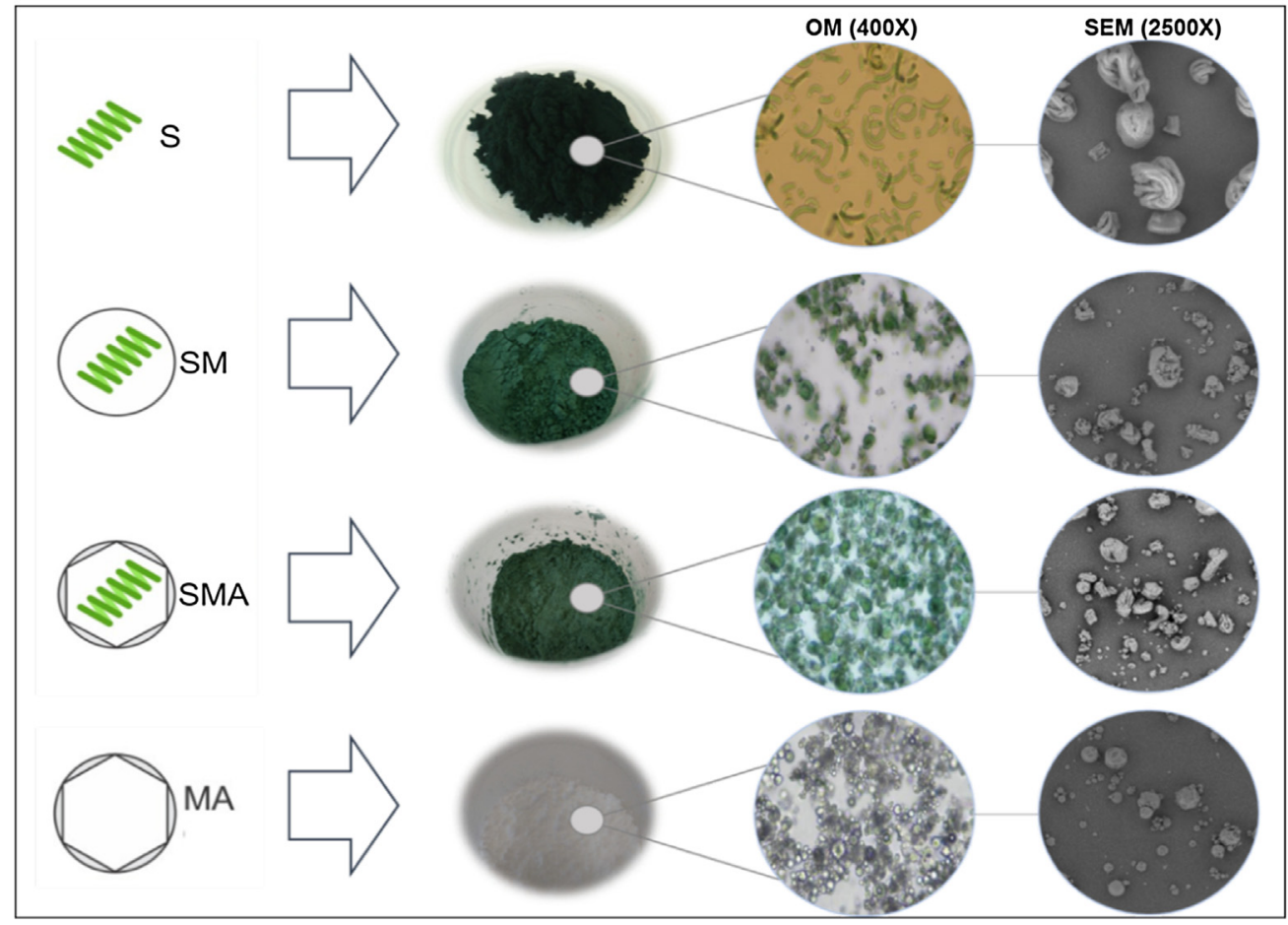

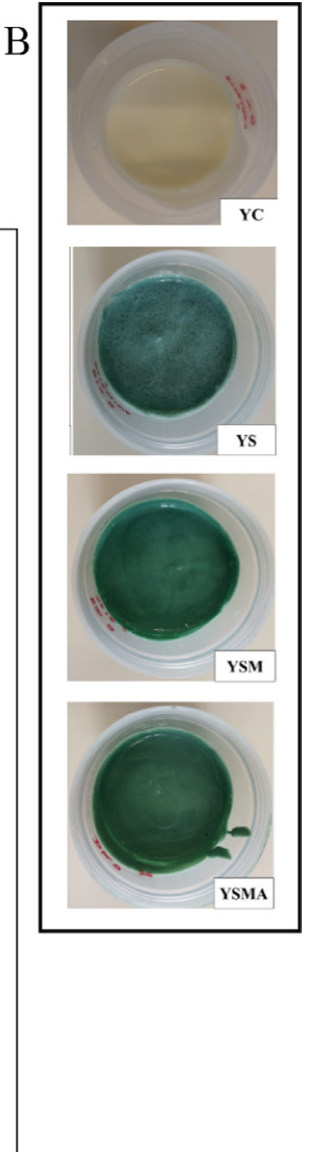

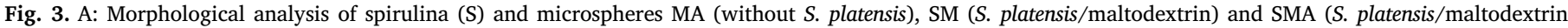
crosslinked with citric acid) examined by optical microscopy (OM) (400X) and scanning electron microscopy (SEM) (2500X). B: Visual appearance of yogurts.

mirabilis was the most resistant. In the case of $P$. aeruginosa, SM (50\% S. platensis), SMA ( $48 \%$ S. platensis) and MA presented better results than S sample and ampicillin. Moreover, the antibacterial activity can also be justified by the presence of the citric acid, which is considered an antimicrobial agent.

The assayed samples showed higher effectiveness against Grampositive bacteria, particularly in the case of $S$ and SMA (Table 2). If compared with the positive controls, samples had lower activities and their MBC could not be determined. Nevertheless, the encapsulation of $S$. platensis increased the antimicrobial activity for $P$. aeruginosa (despite the lower concentration of spirulina, SM: 50\%, SMA: $48 \%$, when compared with S), whereas for the other tested bacteria the MICs were very similar.

Kaushik and Chauhan (2008) described that the methanolic extract of $S$. platensis showed antimicrobial activity against $S$. aureus and E. coli, which is in line with the results obtained in this work. Likewise, Elsheekh, Daboor, Swelim, and Mohamed (2014) describes the extraction of antimicrobial substances from $S$. platensis and their effective action against $E$. coli, $P$. aeruginosa, B. subtilis and the fungus Aspergillus niger.

Summarizing, the microencapsulation of $S$. platensis and the crosslinking reaction of maltodextrin with citric acid have a positive effect in the bioactivity of the microalgae, especially regarding its anti-inflammatory and antibacterial potential.

\subsection{Characterization of functionalized yogurts}

Following the current trend of substituting artificial compounds by natural additives in foods (Carocho, Barreiro, Morales, \& Ferreira, 2014), a set of different functionalized yogurts was prepared using $S$. platensis, either in its free form, or encapsulated in maltodextrin alone or maltodextrin cross-linked with citric acid. For comparison purposes, a group of yogurts was used exactly as bought (free of any functionalizing agent). The laboratorial assays were conducted on three different times: purchase day (when the incorporation was done) and after 4 and 7 days (storage at $4{ }^{\circ} \mathrm{C}$ ). The following codes were defined: i) "blank" yogurt (YC); ii) yogurt with the free form of $S$. platensis (YS); iii) yogurt with $S$. platensis encapsulated in maltodextrin (YSM); iv) yogurt with $S$. platensis encapsulated in maltodextrin cross-linked with citric acid (YSMA), as it can be seen in Fig. 3B. The numbers 0, 4 and 7 indicate the storage days.

Since the effect of each factor yogurt formulation (YF) or storage time (ST), might be affected by the other (i.e., different ST effects according to each $\mathrm{YF}$, or vice versa), the interaction (YF $\times$ ST) was evaluated. In the cases where a significant interaction was found $(p<0.050)$, the multiple comparisons could not be performed. In those cases, the overall conclusions were (when possible) obtained from the corresponding estimated marginal means (EMM) plots.

Starting with the analysis of results for nutritional parameters (Table 3), it could be verified that the interaction among YF and ST $(\mathrm{YF} \times \mathrm{ST})$ was not significant in any case, indicating that the changes occurred along time were not dependent on the YF and vice-versa. In what concerns the effects of each individual factor, it can be concluded that the YF caused significant changes in all cases, except in lactose, while ST had no significant effect $(p<0.050)$ in any parameter. Control yogurts presented higher water contents $(84.6 \mathrm{~g} / 100 \mathrm{~g} \mathrm{fw})$, which might be related with the fact that $S$. platensis, maltodextrin and citric acid were added as dried powders. In-line with the previous observation, functionalized yogurts presented higher fat (3.2 to $3.3 \mathrm{~g} /$ $100 \mathrm{~g} \mathrm{fw})$, protein (6.2 to $6.3 \mathrm{~g} / 100 \mathrm{~g} \mathrm{fw})$ and ash (0.88 to $0.89(84.6 \mathrm{~g} /$ $100 \mathrm{~g} \mathrm{fw}$ ) contents, as well as higher energy value (77 to $80 \mathrm{kcal} / 100 \mathrm{~g}$ 


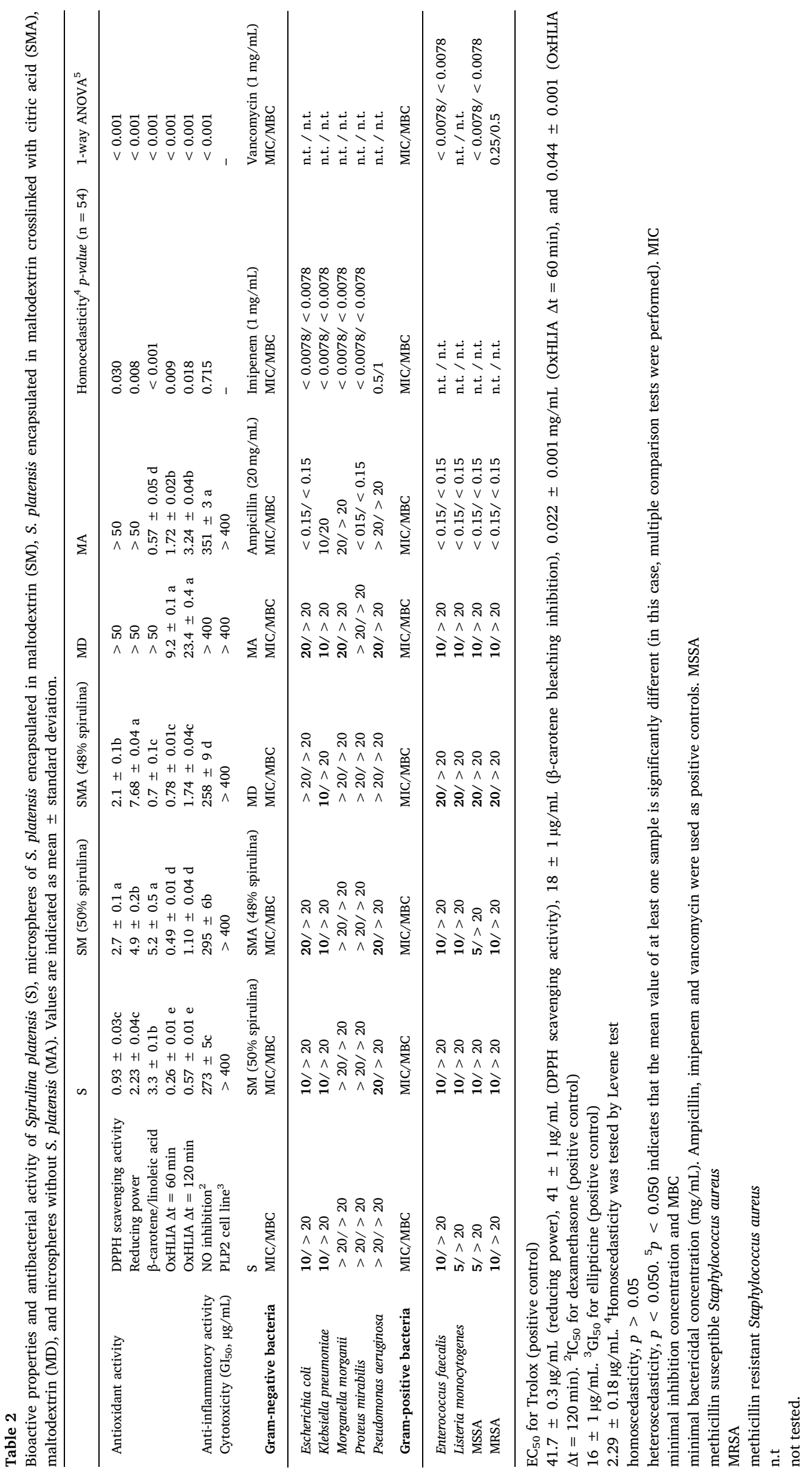



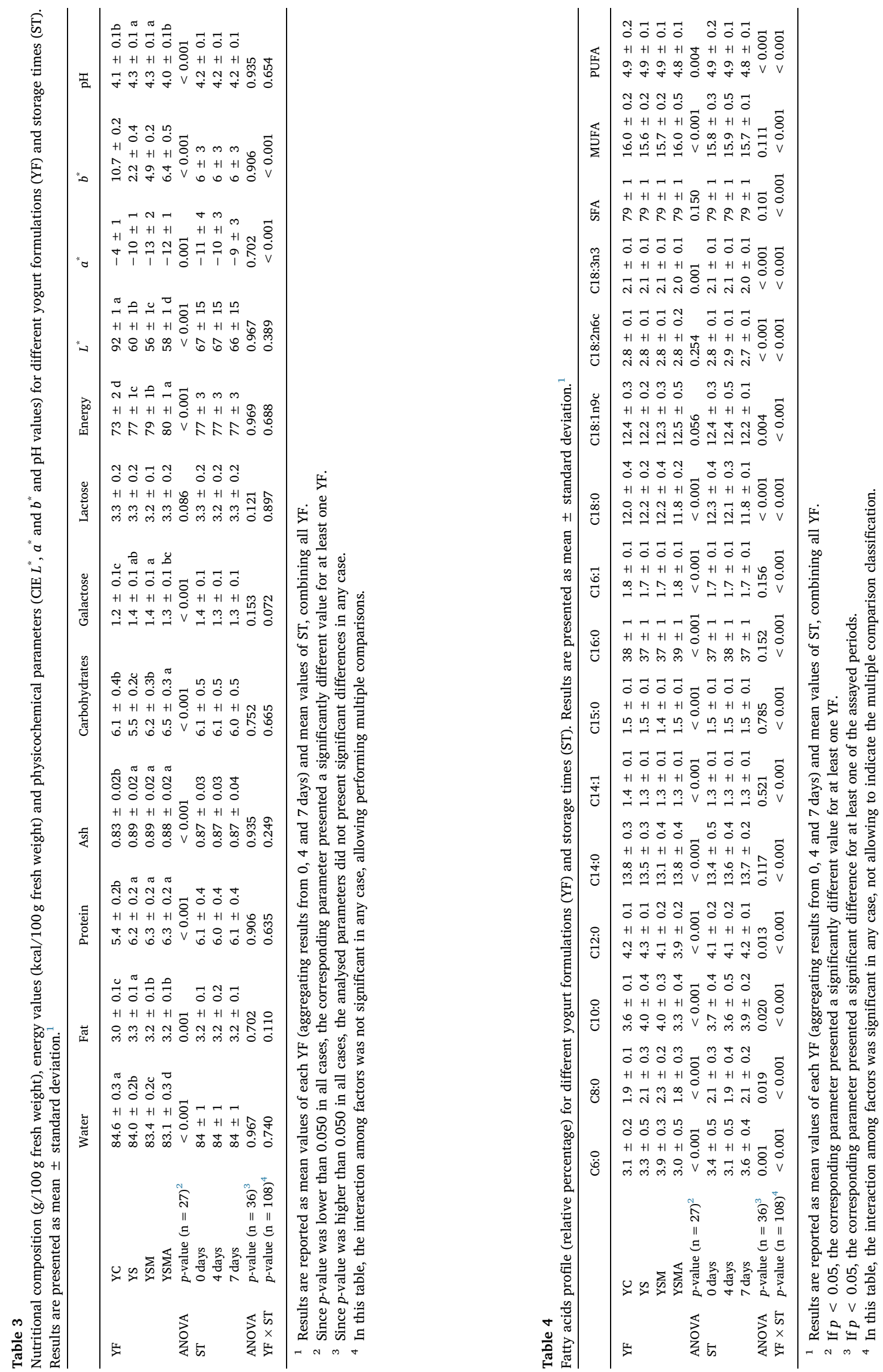


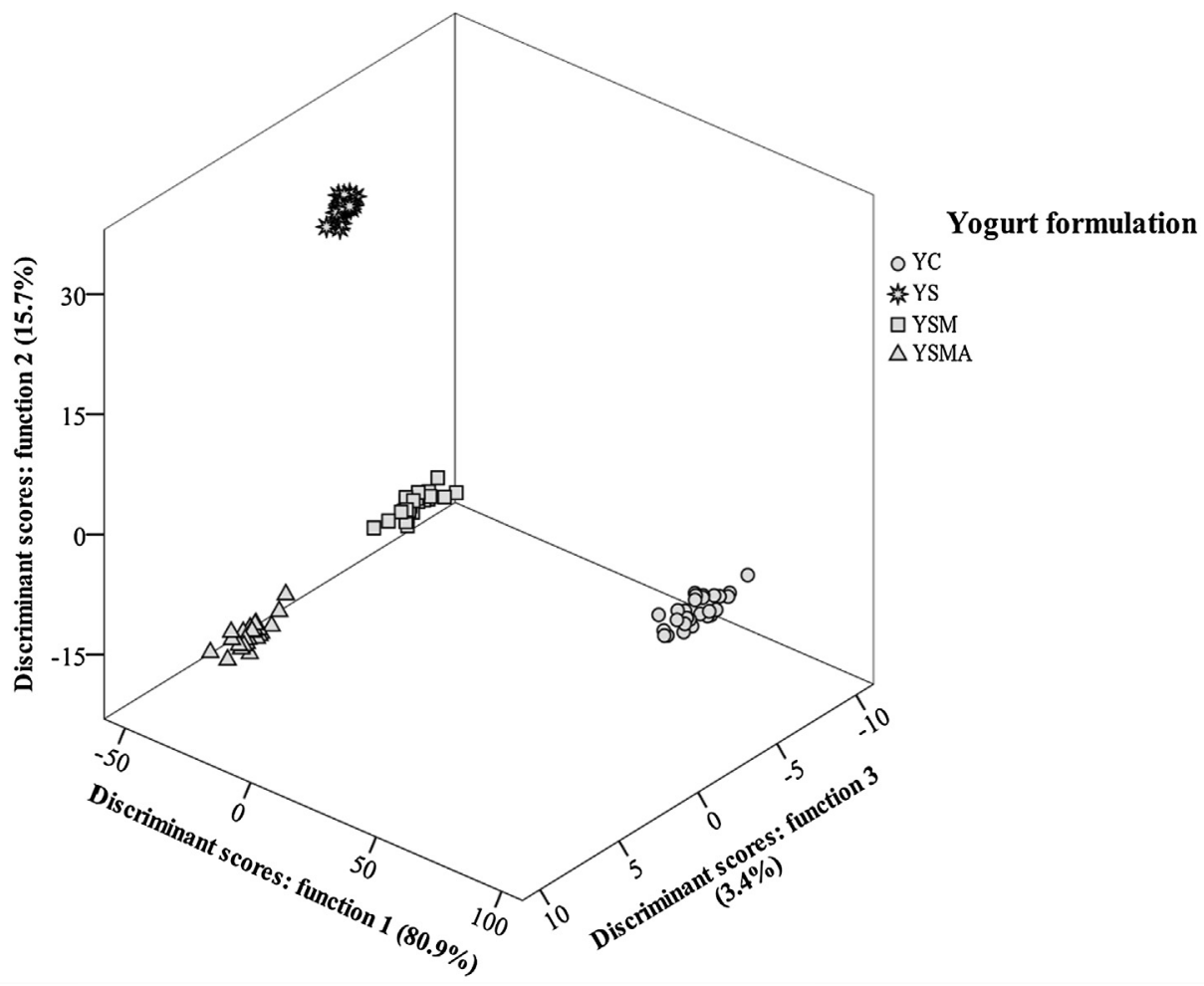

Fig. 4. Three-dimensional distribution of YF markers according to the canonical discriminant functions coefficients defined from the evaluated parameters.

$\mathrm{fw})$. The results for galactose were unforeseen, since it would not be expected to have higher concentrations in functionalized yogurts. Despite the highlighted differences, the results evidenced the maintenance of the nutritional profile typical of natural yogurts (identified here as $\mathrm{YC})$.

The higher effect of YF was observed in colour parameters and $\mathrm{pH}$. In fact, ST caused no significant changes in any case (Table 3 ). In what concerns YF, YC showed higher lightness $\left(L^{*}\right)$ values, which might be justified by the absence of any added powdered ingredient and its whiter colour. The same samples had higher yellowness $\left(b^{*}\right)$, while, as expected, yogurts added with $S$. platensis (either free or encapsulated) presented slightly higher greenness, as indicated by the lower redness $\left(a^{*}\right)$ values. Besides the colour effect, it was possible to observe that yogurts prepared with encapsulated $S$. platensis presented a more homogeneous appearance, while those added with free $S$. platensis presented a kind of a dotted-like effect.

Fatty acid profiles, owing to their effectiveness as indicators of a good conservation process (Barreira, Pereira, Oliveira, \& Ferreira, 2010; Pereira et al., 2016), were also characterized. The results in Table 4 were quantified in relative percentages above $1 \%$, but other minor fatty acids were also detected: C13:0, C15:1, C17:0, C20:0 and C20:1 (however, the complete set of fatty acids was included in the linear discriminant analysis discussed further). Contrarily to nutritional parameters, fatty acids showed different variation patterns along time for each YF, i.e., the interaction among factors was significant in all cases. Therefore, the statistical classification resulting from the multiple comparison tests could not be indicated. Several apparent differences might be identified in Table 4; however, these differences were only unequivocal (a given formulation presenting the same behaviour for all ST, or the ST effect producing an identifiable change independently of YF) in the case of C12:0 (lower in YSMA), C14:0 (lower in YSM) and PUFA (lower after 7 days), as validated by the estimated marginal mean plots (data not shown). Nevertheless, the overall profiles might be considered as being similar among all prepared formulations and assayed times.

Finally, the antioxidant activity of the prepared yogurts was studied, specifically by performing DPPH scavenging activity and reducing power assays. The evolution of $\mathrm{EC}_{50}$ values throughout time is not the same for all formulations, which is in agreement with the significant interaction among factors (YF $\times \mathrm{ST}$ ), for both antioxidant activity assays. In what regards the effect of each individual factor, significant differences were observed, either among different YF, or ST. The most active DPPH scavenger was YSMA $\left(\mathrm{EC}_{50}=9 \mathrm{mg} / \mathrm{mL}\right.$ ), followed by YS and $\mathrm{YSM}\left(\mathrm{EC}_{50}=13 \mathrm{mg} / \mathrm{mL}\right.$ and $15 \mathrm{mg} / \mathrm{mL}$, respectively) and $\mathrm{YC}$ $\left(\mathrm{EC}_{50}=89 \mathrm{mg} / \mathrm{mL}\right)$, which had much lower activity. Actually, the increase obtained in DPPH scavenging activity was better than the one observed in yogurts functionalized with fennel or chamomile (Caleja et al., 2016). The differences in the reducing power were not equally perceivable (YC: $\quad \mathrm{EC}_{50}=29 \mathrm{mg} / \mathrm{mL}, \quad \mathrm{YS}: \quad \mathrm{EC}_{50}=17 \mathrm{mg} / \mathrm{mL}$, YSM: $\mathrm{EC}_{50}=22 \mathrm{mg} / \mathrm{mL}$, YSMA: $\mathrm{EC}_{50}=20 \mathrm{mg} / \mathrm{mL}$ ), despite the higher activity obtained in functionalized yogurts. In terms of ST, no significant effect was observed in DPPH scavenging activity, while reducing power showed a slight decrease in stored samples (4 and 7 days).

\subsubsection{Linear discriminant analysis}

After identifying the previous individual differences, the overall changes were analysed by evaluating all parameters simultaneously, to verify which were more correlated with each prepared YF. Accordingly, a linear discriminant analysis (LDA) was performed to assess the correlations among YF (categorical dependent variables) and the obtained results (quantitative independent variables). The significant independent variables were selected with the stepwise method of LDA, following the Wilks' $\lambda$ test. Only variables with a statistically significant classification performance $(p<0.050)$ were maintained by the statistical model.

The three defined discriminant functions included 100\% (first function: $80.9 \%$; second function: $15.7 \%$; third function: $3.4 \%$ ) of the observed variance (Fig. 4). Among the 35 analysed variables, the discriminant model selected moisture, $L^{*}, b^{*}, a^{*}$, lactose, C14:1, C15:0, C15:1, C17:0, C18:3n3, C20:0, C20:1, SFA, DPPH scavenging activity, and reducing power, as those having significant discriminant ability.

Within the selected variables, function 1 was more correlated with 
$L^{*}$ and its main effect was separating markers corresponding to YC (highest $L^{*}$ values) in the positive side of function 1 axis. Function 2, by its side, was more highly correlated with $b^{*}$, discriminating samples containing free $S$. platensis (YS) from those added with the encapsulated forms (YSM and YSMA), due to its lower values of yellowness ( $\left.b^{*}\right)$. As it might be observed by the three-dimensional placement of markers corresponding to different YF, the most similar formulations were YSM and YSMA, which could only be separated with the contribution of function 3, mostly correlated with DPPH scavenging activity and reducing power, both presenting lower $\mathrm{EC}_{50}$ values in the case of YSMA.

In the performed LDA, the classification performance was $100 \%$ accurate, either for original grouped cases, as well as for the cross-validated grouped ones.

Overall, YSMA turned out to be the best solution to incorporate $S$. platensis in yogurt as it maintained nutritional and fatty acid profiles, provided a more appealing colour and, most of all, improved the antioxidant activity at a greater extent. In the study carried out by Francisco et al. (2018), the incorporation of Agaricus bisporus extract encapsulated in maltodextrin crosslinked with citric acid in yogurts, increased the antioxidant activity (throughout 7 days of storage). This effect can be justified by the effective reaction of maltodextrin with citric acid providing effective crosslinking. Another hypothesis is the possible reaction between $S$. platensis and citric acid, which might generate compounds that increase the antioxidant activity.

\section{Conclusions}

The spray-drying technique was tested to microencapsulate $S$. platensis using maltodextrin alone or crosslinked with citric acid as wall materials. Microencapsulation was used to overcome constraints related with product's inhomogeneity and maintain the bioactivity. S. platensis was successfully encapsulated. The microspheres showed good thermal stability, superior, or comparable, to the one of base materials, and showed anti-inflammatory activity higher than the one of free $S$. platensis, even if their $S$. platensis content was only $50 \%$. In addition, the produced microspheres did not show cytotoxicity indicating their suitability to be used in food applications, here demonstrated by the development of functional yogurts.

The incorporation of $S$. platensis in its encapsulated form showed the advantages of using this form over their direct use (i.e., without microencapsulation) in yogurts. Apart from the increased homogeneity of both YSM and YSMA yogurts, it was possible to conclude (from the discriminant analysis) that the SMA form is the most recommended for yogurt functionalization. It was able to maintain the nutritional profile, and improve the antioxidant activity throughout storage time. Furthermore, and based on qualitative analysis, the unpleasant fish-like odor of S. platensis was not perceptible, and the strong green color was attenuated, when the microencapsulation forms were used. These preliminary results on color and odor evaluation need further validation by conducting sensory analysis, and might be considered in future work.

\section{Ethics}

This research does not include any human subjects or animal experiments.

\section{Declaration of Competing Interest}

The authors declare that they do not have any conflict of interest.

\section{Acknowledgements}

The authors are grateful to the Foundation for Science and Technology (FCT, Portugal) and FEDER under Program PT2020 for financial support to CIMO (UID/AGR/00690/2019); L. Barros, J.C.M. Barreira, R. C. Calhelha, I.P. Fernandes and A. Fernandes thank the national funding by FCT , P.I., through the institutional scientific employment program-contract for their contracts; and C. Pereira also thanks for her contract, though the celebration of program-contract foreseen in No. 4, 5 and 6 of article $23^{\circ}$ of Decree-Law No. 57/2016, of 29th August, amended by Law No. 57/2017, of 19th July.

Associate Laboratory LSRE-LCM - UID/EQU/50020/2019 - funded by national funds through FCT/MCTES (PIDDAC), and Project NORTE01-0145-FEDER-000006, funded by NORTE 2020, under the PT2020 Partnership Agreement through ERDF.

\section{Appendix A. Supplementary material}

Supplementary data to this article can be found online at https:// doi.org/10.1016/j.jff.2019.103427.

\section{References}

Abalde, J. (1998). Purification and characterization of phycocyanin from the marine cyanobacterium Synechococcus sp. 109201. Plant Science, 136, 109-120.

Abreu, R. M. V., Ferreira, I. C. F. R., Calhelha, R. C., Lima, R. T., Vasconcelos, M. H., Adega, F., ... Queiroz, M. J. R. P. (2011). Anti-hepatocellular carcinoma activity using human HepG2 cells and hepatotoxicity of 6-substituted methyl 3-aminothieno[3,2-b] pyridine-2- carboxylate derivatives: In vitro evaluation, cell cycle analysis and QSAR studies. European Journal of Medicinal Chemistry, 46, 5800-5806.

Agustini, T. W., Maruf, W. F., Widayat, Suzery, M., Hadiyanto, \& Benjakul, S. (2016). Application of spirulina platensis on ice cream and soft cheese with respect to their nutritional and sensory perspectives. Jurnal Teknologi, 78, 245-251.

Agustini, T. W., Soetrisnanto, D., \& Maruf, W. F. (2017). Study on chemical, physical, microbiological and sensory of yoghurt enriched by Spirulina platensis. International Food Research Journal, 24, 367-371.

Agustini, T. W., Suzery, M., Sutrisnanto, D., Maruf, W. F., \& Hadiyanto (2015). Comparative study of bioactive substances extracted from fresh and dried Spirulina sp. Procedia Environmental Sciences, 23(Ictcred 2014), 282-289.

Ak, B., Avşaroğlu, E., Işık, O., Özyurt, G., Kafkas, E., \& Uslu, L. (2016). Nutritional and physicochemical characteristics of bread enriched with microalgae Spirulina platensis. International Journal of Engineering Research and Application, 6, 30-38.

Al-qahtani, W. H., \& Binobead, M. A. (2018). Anti-inflammatory, antioxidant and antihepatotoxic effects of Spirulina platensis against D -galactosamine induced hepatotoxicity in rats. Saudi Journal of Biological Sciences, 1-6.

Almeida, H. H. S., Barros, L., Barreira, J. C. M., Calhelha, R. C., Heleno, S. A., Sayer, C., .. Ferreira, I. C. F. R. (2018). Bioactive evaluation and application of different formulations of the natural colorant curcumin (E100) in a hydrophilic matrix (yogurt). Food Chemistry, 261(December 2017), 224-232.

AOAC. (2016). Official methods of analysis of AOAC International. USA: AOAC International.: (D. G. W. L. Jr; Ed.) (20th ed.).

Azeredo, H. M. C., \& Waldron, K. W. (2016). Crosslinking in polysaccharide and protein films and coatings for food contact - A review. Trends in Food Science and Technology, 52, 109-122.

Azzi, A. (2018). Many tocopherols, one vitamin E. Molecular Aspects of Medicine, 61, 92-103.

Bach, Q., \& Chen, W. (2017). Pyrolysis characteristics and kinetics of microalgae via thermogravimetric analysis (TGA): A state-of-the-art review. Bioresource Technology, 246, 88-100.

Barkallah, M., Dammak, M., Louati, I., Hentati, F., Hadrich, B., Mechichi, T., ... Abdelkafi, S. (2017). Effect of Spirulina platensis fortification on physicochemical, textural, antioxidant and sensory properties of yogurt during fermentation and storage. LWT Food Science and Technology, 84, 323-330.

Barreira, J. C. M., Pereira, J. A., Oliveira, M. B. P. P., \& Ferreira, I. C. F. R. (2010). Sugars profiles of different chestnut (Castanea sativa Mill.) and almond (Prunus dulcis) cultivars by HPLC-RI. Plant Foods for Human Nutrition, 65, 38-43.

Barros, L., Pereira, E., Calhelha, R. C., Dueñas, M., Carvalho, A. M., Santos-Buelga, C., \& Ferreira, I. C. F. R. (2013). Bioactivity and chemical characterization in hydrophilic and lipophilic compounds of Chenopodium ambrosioides L. Journal of Functional Foods, 5, 1732-1740.

Batista, A. P., Gouveia, L., Bandarra, N. M., Franco, J. M., \& Raymundo, A. (2013). Comparison of microalgal biomass profiles as novel functional ingredient for food products. Algal Research, 2, 164-173.

Bennett, A., \& Bogorad, L. (1973). Complementary chromatic adaption in a filamentous blue-green alga. The Journal of Cell Biology, 58, 419-435.

Bharat Helkar, P., \& Sahoo, A. (2016). Review: Food industry by-products used as a functional food ingredients. International Journal of Waste Resources, 6.

Bimbo, F., Bonanno, A., Nocella, G., Viscecchia, R., Nardone, G., De Devitiis, B., \& Carlucci, D. (2017). Consumers' acceptance and preferences for nutrition-modified and functional dairy products: A systematic review. Appetite, 113, 141-154.

Caleja, C., Barros, L., Antonio, A. L., Carocho, M., Oliveira, M. B. P. P., \& Ferreira, I. C. F. R. (2016). Fortification of yogurts with different antioxidant preservatives: A comparative study between natural and synthetic additives. Food Chemistry, 210, $262-268$.

Carocho, M., Barreiro, M. F., Morales, P., \& Ferreira, I. C. F. R. (2014). Adding molecules to food, pros and cons: A review on synthetic and natural food additives. 
Comprehensive Reviews in Food Science and Food Safety, 13, 377-399.

Castro-Cabado, M., Casado, A. L. \& San Román, J. (2016a). Bio-based thermosets: Effect of the structure of polycarboxylic acids on the thermal crosslinking of maltodextrins. European Polymer Journal, 78, 91-105.

Castro-Cabado, M., Casado, A. L., \& San Román, J. (2016b). Effect of CaO in the thermal crosslinking of maltodextrin and citric acid: A cooperative action of condensation and ionic interactions. Journal of Applied Polymer Science, 133(46), 1-10.

Castro-Cabado, M., Parra-Ruiz, F. J., Casado, A. L., \& San Román, J. (2016). Thermal crosslinking of maltodextrin and citric acid. Methodology to control the polycondensation reaction under processing conditions. Polymers and Polymer Composites, 24, 643-654.

Chaiklahan, R., Chirasuwan, N., \& Bunnag, B. (2012). Stability of phycocyanin extracted from Spirulina sp.: Influence of temperature, $\mathrm{pH}$ and preservatives. Process Biochemistry, 47(4), 659-664.

Chen, J., Liu, K. S., Yang, T., Hwang, J., Chan, Y., \& Lee, I. (2012). Spirulina and Cphycocyanin reduce cytotoxicity and inflammation-related genes expression of microglial cells. Nutritional Neuroscience, 15, 252-258.

Christaki, E., Florou-Paneri, P., \& Bonos, E. (2011). Microalgae: A novel ingredient in nutrition. International Journal of Food Sciences and Nutrition, 62, 794-799.

Comunian, T. A., Chaves, I. E., Thomazini, M., Moraes, I. C. F., Ferro-Furtado, R., de Castro, I. A., \& Favaro-Trindade, C. S. (2017). Development of functional yogurt containing free and encapsulated echium oil, phytosterol and sinapic acid. Food Chemistry, 237, 948-956.

Corrêa, R. C. G., de Souza, A. H. P., Calhelha, R. C., Barros, L., Glamoclija, J., Sokovic, M., ... Ferreira, I. C. F. R. (2015). Bioactive formulations prepared from fruiting bodies and submerged culture mycelia of the Brazilian edible mushroom Pleurotus ostreatoroseus Singer. Food Function, 6, 2155-2164.

Dias, D. R., Botrel, D. A., Fernandes, R. V. D. B., \& Borges, S. V. (2017). Encapsulation as a tool for bioprocessing of functional foods. Current Opinion in Food Science, 13, 31-37.

Dias, M. I., Ferreira, I. C. F. R., \& Barreiro, M. F. (2015). Microencapsulation of bioactives for food applications. Food Function, 6, 1035-1052.

El-sheekh, M. M., Daboor, S. M., Swelim, M. A., \& Mohamed, S. (2014). Production and characterization of antimicrobial active substance from Spirulina platensis. Iranian Journal of Microbiology, 6, 112-119.

FDA - Food and Drug Administration (2002). GRAS notification "Spirulina" microalgae.

Fernandes, A., Barreira, J. C. M., Barros, L., Mendonça, A., Ferreira, I. C. F. R., \& Ruivo de Sousa, F. (2018). Chemical and physicochemical changes in Serrana goat cheese submitted to extra-long ripening periods. LWT - Food Science and Technology, 87, $33-39$.

Francisco, C. R. L., Heleno, S. A., Fernandes, I. P. M., Barreira, J. C. M., Calhelha, R. C., Barros, L., ... Barreiro, M. F. (2018). Functionalization of yogurts with Agaricus bisporus extracts encapsulated in spray-dried maltodextrin crosslinked with citric acid. Food Chemistry, 245, 845-853.

Gahruie, H. H., Eskandari, M. H., Mesbahi, G., \& Hanifpour, M. A. (2015). Scientific and technical aspects of yogurt fortification: A review. Food Science and Human Wellness, $4,1-8$.

Ghorbanzade, T., Jafari, S. M., Akhavan, S., \& Hadavi, R. (2017). Nano-encapsulation of fish oil in nano-liposomes and its application in fortification of yogurt. Food Chemistry, 216, 146-152.

Gómez-Coronado, D. J., Ibañez, E., Rupérez, F. J., \& Barbas, C. (2004). Tocopherol measurement in edible products of vegetable origin. Journal of Chromatography A, 1054, 227-233.

Gouveia, L., Batista, A. P., Sousa, I., Raymundo, A., \& Bandarra, N. M. (2008). Microalgae in novel food product. In K. N. Papadopoulos (Ed.), Food chemistry research developments (p. 107).

Hafsa, Y. A., Amel, D., Samia, S., Sidahmed, S., \& Ali, B. (2014). Evaluation of nutritional and sensory properties of bread enriched with Spirulina. Annals Food Science and Technology, 15.

İlter, I., Akyıl, S., Demirel, Z., Koç, M., Conk-Dalay, M., \& Kaymak-Ertekin, F. (2018). Optimization of phycocyanin extraction from Spirulina platensis using different techniques. Journal of Food Composition and Analysis, 70, 78-88.

Jang, S. A., Park, D. W., Kwon, J. E., Song, H. S., Park, B., Jeon, H., ... Kang, S. C. (2017). Quinic acid inhibits vascular inflammation in TNF- $\alpha$-stimulated vascular smooth muscle cells. Biomedicine and Pharmacotherapy, 96, 563-571.

Kaushik, P., \& Chauhan, A. (2008). In vitro antibacterial activity of laboratory grown culture of Spirulina platensis. Indian Journal of Microbiology, 48, 348-352.

Kumar, D., Dhar, D. W., Pabbi, S., Kumar, N., \& Walia, S. (2014). Extraction and purification of C-phycocyanin from Spirulina platensis (CCC540). Indian Journal of Plant
Physiology, 19, 184-188.

Li, F., Srivatsa, S. C., Batchelor, W., \& Bhattacharya, S. (2017). A study on growth and pyrolysis characteristics of microalgae using thermogravimetric analysis-infrared spectroscopy and synchrotron Fourier transform infrared spectroscopy. Bioresource Technology, 229, 1-10.

Lockowandt, L., Pinela, J., Roriz, C. L., Pereira, C., Abreu, R. M. V., Calhelha, R. C., .. Ferreira, I. C. F. R. (2019). Chemical features and bioactivities of cornflower (Centaurea cyanus L.) capitula: The blue flowers and the unexplored non-edible part. Industrial Crops and Products, 128, 496-503.

Manzi, P., Marconi, S., Aguzzi, A., \& Pizzoferrato, L. (2004). Commercial mushrooms: Nutritional quality and effect of cooking. Food Chemistry, 84, 201-206.

Matos, J., Cardoso, C., Bandarra, N. M., \& Afonso, C. (2017). Function Microalgae as healthy ingredients for functional food: A review. Food \& Function, 8, 2672-2685.

Melgar, B., Dias, M. I., Ciric, A., Sokovic, M., Garcia-Castello, E. M., Rodriguez-Lopez, A. D., ... Ferreira, I. C. R. F. (2018). Bioactive characterization of Persea americana Mill. by-products: A rich source of inherent antioxidants. Industrial Crops and Products.

Mühling, M., Belay, A., \& Whitton, B. A. (2005). Variation in fatty acid composition of Arthrospira (Spirulina) strains. Journal of Applied Phycology, 17, 137-146.

Özyurt, G., Uslu, L., Yuvka, I., Gökdoğan, S., Atci, G., Ak, B., \& Işik, O. (2015). Evaluation of the cooking quality characteristics of pasta enriched with Spirulina platensis. Journal of Food Quality, 38, 268-272.

Paliwal, C., Bhayani, K., Maurya, R., \& Mishra, S. (2015). Antioxidant, anti-nephrolithe activities and in vitro digestibility studies of three different cyanobacterial pigment extracts. Marine Drugs, 13, 5384-5401.

Pathak, T. S., Yun, J. H., Lee, J., \& Paeng, K. J. (2010). Effect of calcium ion (cross-linker) concentration on porosity, surface morphology and thermal behavior of calcium alginates prepared from algae (Undaria pinnatifida). Carbohydrate Polymers, 81, 633-639.

Pereira, E., Barros, L., Barreira, J. C. M., Carvalho, A. M., Antonio, A. L., \& Ferreira, I. C. F. R. (2016). Electron beam and gamma irradiation as feasible conservation technologies for wild Arenaria montana L.: Effects on chemical and antioxidant parameters. Innovative Food Science and Emerging Technologies, 36, 269-276.

Ribeiro, A., Ruphuy, G., Lopes, J. C., Dias, M. M., Barros, L., Barreiro, F., \& Ferreira, I. C. F. R. (2015). Spray-drying microencapsulation of synergistic antioxidant mushroom extracts and their use as functional food ingredients. Food Chemistry, 188, 612-618.

Russo, R., Malinconico, M., \& Santagata, G. (2007). Effect of cross-linking with calcium ions on the physical properties of alginate films. Biomacromolecules.

Santiago-Morales, I. S., Trujillo-Valle, L., \& Márquez-Rocha, F. J. (2018). Tocopherols, phycocyanin and superoxide dismutase from microalgae: As potential food antioxidants. Applied Food Biotechnology, 5, 19-27.

Saran, S., Puri, N., Jasuja, N. D., \& Sharma, G. (2016). Optimization, purification and characterization of phycocyanin from Spirulina platensis, pp. 15-21.

Sarmento, A., Barros, L., Fernandes, Â., Carvalho, A. M., \& Ferreira, I. C. F. R. (2015) Valorization of traditional foods: Nutritional and bioactive properties of Cicer arietinum L. and Lathyrus sativus L. pulses. Journal of the Science of Food and Agriculture, 95, 179-185.

Shalaby, E. A., \& Shanab, S. M. M. (2013). Comparison of DPPH and ABTS assays for determining antioxidant potential of water and methanol extracts of Spirulina platensis. Journal of the American Geriatrics Society, 42, 556-564.

Sharoba, A. (2014). Nutritional calue of Spirulina and its use in the preparation of some complementary baby food formulas. Journal of Food and Dairy Science, 5, 517-538.

Soni, B., Kalavadia, B., Trivedi, U., \& Madamwar, D. (2006). Extraction, purification and characterization of phycocyanin from Oscillatoria quadripunctulata-Isolated from the rocky shores of Bet-Dwarka, Gujarat, India. Process Biochemistry, 41, 2017-2023.

Soni, R. A., Sudhakar, K., \& Rana, R. S. (2017). Spirulina - From growth to nutritional product: A review. Trends in Food Science and Technology, 69, 157-171.

Wan, D., Wu, Q., \& Kuča, K. (2016). Spirulina. In Nutraceuticals (pp. 569-583)

Wen, J., Chen, G., \& Alany, R. G. (2014). Theories and concepts of nano materials, nanoand microencapsulation. In H.-. S. Kwak (Ed.). Nano-and micoencapsulation for foods. Wiley Blackwell: Coreia.

Zhang, L., Zeng, X., Fu, N., Tang, X., Sun, Y., \& Lin, L. (2018). Maltodextrin: A consummate carrier for spray-drying of xylooligosaccharides. Food Research International, 106, 383-393.

Zielinski, A. A. F., Haminiuk, C. W. I., Alberti, A., Nogueira, A., Demiate, I. M., \& Granato, D. (2014). A comparative study of the phenolic compounds and the in vitro antioxidant activity of different Brazilian teas using multivariate statistical techniques. Food Research International, 60, 246-254. 